\title{
Tumor Invasion of the Mucosa
}

National Cancer Institute

\section{Source}

National Cancer Institute. Tumor Invasion of the Mucosa. NCI Thesaurus. Code C160685.

A finding indicating that a neoplastic cellular infiltrate has broken the basement membrane and invaded the lamina propria. 